\title{
Bioenergetics adaptations and redox homeostasis in pregnancy and related disorders
}

\author{
Lissette Sanchez-Aranguren ${ }^{1}\left[\right.$ [ $\cdot$ Sarah Nadeem ${ }^{1}$
}

Received: 22 September 2020 / Accepted: 21 June 2021 / Published online: 1 July 2021

(c) The Author(s) 2021

\begin{abstract}
Pregnancy is a challenging physiological process that involves maternal adaptations to the increasing energetics demands imposed by the growing conceptus. Failure to adapt to these requirements may result in serious health complications for the mother and the baby. The mitochondria are biosynthetic and energy-producing organelles supporting the augmented energetic demands of pregnancy. Evidence suggests that placental mitochondria display a dynamic phenotype through gestation. At early stages of pregnancy placental mitochondria are mainly responsible for the generation of metabolic intermediates and reactive oxygen species (ROS), while at later stages of gestation, the placental mitochondria exhibit high rates of oxygen consumption. This review describes the metabolic fingerprint of the placental mitochondria at different stages of pregnancy and summarises key signs of mitochondrial dysfunction in pathological pregnancy conditions, including preeclampsia, gestational diabetes and intrauterine growth restriction (IUGR). So far, the effects of placental-driven metabolic changes governing the metabolic adaptations occurring in different maternal tissues in both, healthy and pathological pregnancies, remain to be uncovered. Understanding the function and molecular aspects of the adaptations occurring in placental and maternal tissue's mitochondria will unveil potential targets for further therapeutic exploration that could address pregnancyrelated disorders. Targeting mitochondrial metabolism is an emerging approach for regulating mitochondrial bioenergetics. This review will also describe the potential therapeutic use of compounds with a recognised effect on mitochondria, for the management of preeclampsia.
\end{abstract}

Keywords Pregnancy $\cdot$ Mitochondria $\cdot$ Mitochondrial dysfunction $\cdot$ Mitochondrial-targeted drugs

\section{Introduction}

Mitochondria are cellular organelles involved in the production of energy to support cell growth and proliferation. Recently, mitochondria are not only recognised as biosynthetic organelles but as important mediators in cell signalling pathways [1]. In the context of physiological processes such as pregnancy, the progress of placentation and foetal development require large amounts of energy and the mitochondria are key to sustain these increased metabolic demands. Besides, the maternal tissues are expected to adapt to these highly energetic events and to promote effective energy supply to the maternal-foetal interface.

Lissette Sanchez-Aranguren

1.sanchez-aranguren2@aston.ac.uk

1 College of Health and Life Sciences, Aston Medical School, Aston University, Birmingham, UK
Pregnancy encompasses physiological changes mainly driven by the placenta. However, the way the maternal tissues' response to these demands is argued to be involved in the progression of a successful pregnancy. At early stages, usually during the first two trimesters, pregnancy allows the deposition of lipids in maternal tissues. This period is noticed as an "anabolic phase" [2] characterised by an increase in maternal fat storage $[3,4]$ and progressive decrease in fasting glucose levels while pregnancy advances linked to a $10 \%$ reduction in insulin sensitivity as compared with pregravid estimates [5]. Interestingly, although fasting glucose levels are reduced, hepatic glucose production (through gluconeogenesis and glycogenolysis) is increased, leading to an increase in fasting insulin. Consequently, the decrease in maternal hepatic insulin sensitivity results in enhanced hepatic glucose production [5]. Towards late gestation, the maternal metabolic status is characterised by a "catabolic phase" in where the peripheral insulin sensitivity is further reduced and peritoneal and subcutaneous 
fat storage is broken-down serving as a calorie source for mother and foetus $[2,5]$. These events are so far well described and demonstrate the existence of active variations in the energetic requirements throughout pregnancy.

The maternal endothelium can respond to cellular signals from the mother and the foetus and these adaptations may involve a fine-tuned regulation of the by-products of metabolic pathways. Research suggests that both, placenta and maternal endothelium are highly energetic tissues using oxygen to produce energy through oxidative phosphorylation (OXPHOS) via mitochondria. This process also supports reactive oxygen species (ROS) formation that regulates intracellular signalling and tissue adaptations $[6,7]$. ROS are increasingly recognised as signalling molecules regulating a myriad of physiological processes [7, 8]. Nevertheless, an imbalance in the cellular production and antioxidant defences [9], known as oxidative stress, triggers various cellular events that disturb signalling pathways leading to the onset of oxidative stress-related conditions [10].

So far, oxidative stress has been implicated as a mediator in the pathophysiology of a variety of pregnancy-related disorders, such as preeclampsia, intrauterine growth restriction (IUGR) and gestational diabetes [11-14]. Therefore, understanding the molecular mechanisms involved in the redox homeostasis during pregnancy is key to identify therapeutic targets that could potentially address these gestational disorders. This review aims to describe the role of mitochondria to sustain and to adapt to the high metabolic demands imposed by pregnancy, focusing on identifying the metabolic fingerprint of placental mitochondria at different stages of pregnancy and recognising the mitochondrial perturbations associated with pathogenic outcomes in maternal tissues. Emerging evidence suggests that targeting mitochondrial metabolism in pregnancy might be of therapeutic interest. Therefore, this review also summarises current mitochondrial-targeted drugs and their observed effect on the progression of gestation and outcomes associated with preeclampsia.

\section{Mitochondria: bioenergetics and signalling organelles}

Mitochondria play a key role in the production of energy in eukaryotic cells. These double membrane-bound organelles support most of the cellular energetic demands by generating adenosine triphosphate (ATP) [15]. Also, mitochondria generate ROS, regulate cytosolic calcium levels and modulate apoptosis [16].

From the bioenergetics perspective, mitochondria are responsible for two major processes, the production of ATP and the generation of metabolic intermediates [17]. The mitochondrial production of ATP relies on the oxidation of metabolic substrates by the tricarboxylic acid cycle (TCA) and the electron transport chain (ETC) in the presence of oxygen. The TCA cycle generates metabolic intermediates and reducing equivalents that would feed the ETC and serve as building blocks for macromolecule biosynthesis [17]. Both, the TCA cycle and the ETC are tightly coordinated as the oxidation of reducing equivalents, $\mathrm{NADH}$ and $\mathrm{FADH}_{2}$, are required for the TCA [17, 18] (Fig. 1).

The mitochondrial oxidation of substrates requires oxygen as the last acceptor of electrons in the ETC [19]. Therefore, the mitochondria are one of the most important sites for ROS formation resulting from the reduction of molecular oxygen to produce superoxide. The production of mitochondrial reactive oxygen species (mtROS) is strongly regulated by antioxidant enzymes such as superoxide dismutase (SOD) that convert superoxide to hydrogen peroxide $\left(\mathrm{H}_{2} \mathrm{O}_{2}\right)$. Several enzymes including peroxiredoxins, glutathione peroxidases and catalase remove $\mathrm{H}_{2} \mathrm{O}_{2}$ and hence, regulate intracellular ROS levels [7]. In biological systems, mtROS are known to play a crucial role in the adaptation to different stimuli including hypoxia, cytokine stimulation and calcium influx [7]. Although the redox biology of pregnancy and associated complications remain largely unexplored, evidence suggests that dysregulation of mtROS homeostasis causes mitochondrial dysfunction and oxidative stress and these events are associated with the onset of adverse gynaecological outcomes [20].

\section{The mitochondria during pre-implantation and early development}

The mitochondria are the most abundant cytoplasmic organelles in oocytes. These organelles experience substantial changes during preimplantation development to provide for the energetic requirements of the embryo and participate in key signalling cellular pathways [21, 22]. The mature oocyte contains large amounts of mitochondria accounting for approximately $23 \%$ of its volume [23]. It is the mature oocyte that provides with the mitochondrial cargo for the embryo and although the spermatozoa do not provide with mitochondria, these organelles are important for sperm motility and male fertility [24]. After implantation, the blastocyst experience a significant metabolic shift with enhanced reliance on glycolysis for ATP production [25]. Still, it has been reported that OXPHOS contributes to the generation of ROS production during embryo development [26]. These observations indicate that mitochondria are crucial organelles of major importance for the production of mitochondrial-derived ROS participating in cell signalling events during embryogenesis. 


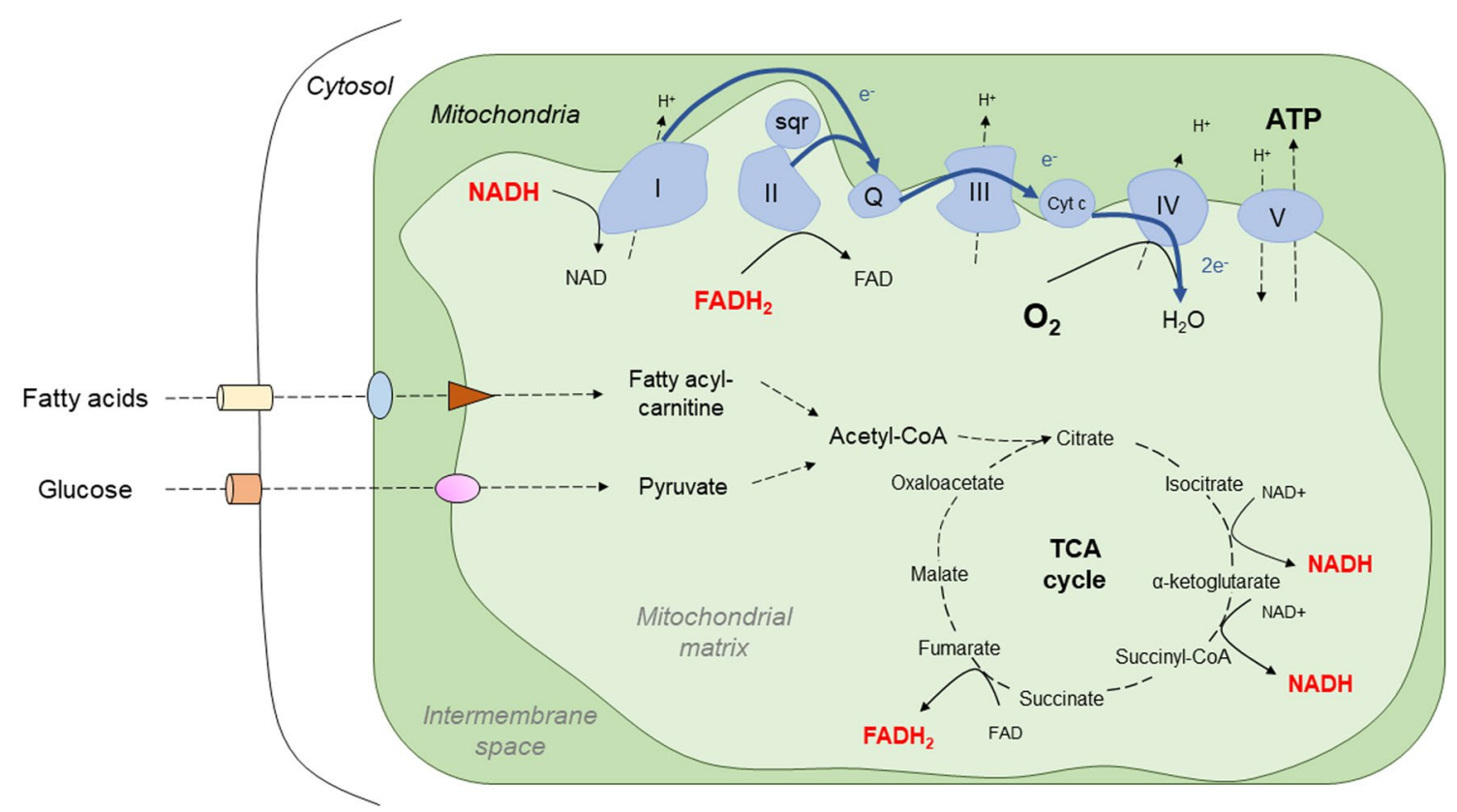

Fig. 1 Schematic overview of mitochondrial bioenergetics of the electron transport chain and the tricarboxylic acid cycle. $\mathrm{H}^{+}$, hydrogen; sqr, sulfide quinone oxidoreductase; Q, coenzyme Q; Cyt c, cytochrome c; $\mathrm{e}^{-}$, electron

\section{Placental mitochondria at early pregnancy}

The development of the placenta initiates at embryo implantation, followed by the migration of trophoblast cells into the maternal decidua and the invasion and remodelling of maternal spiral arteries [27]. Several cell types compose the human placenta. In particular, the villous trophoblast cell linage, predominantly cytotrophoblasts (CT) and the syncytiotrophoblast (ST) are involved in key placental functions [28]. The invasion and remodelling of spiral arteries occur in an environment of low oxygen tension, yet, the recurrent invasion provides increased blood perfusion and oxygen to the placenta. This theory has been proven by polarographic electrode measurements in vivo, where it has been shown that the foetal-placental oxygen tension at $8-10$ weeks of gestation is approximately $17.9 \pm 6.9 \mathrm{~mm} \mathrm{Hg}$ while at 12-13 weeks the oxygen tension increases to $60.7 \pm 8.5 \mathrm{~mm} \mathrm{Hg}[29]$. These observations also suggest that variations in oxygen bioavailability are a normal feature of healthy pregnancies. Besides, it is inferred that the increased availability of oxygen may promote OXPHOS and the formation of physiological levels of ROS. Supporting this evidence, the role of hypoxia in the differentiation of $\mathrm{CT}$ has been well documented. Low oxygen ( $2 \%$ oxygen) promotes the differentiation of isolated first trimester CT into extravillous trophoblasts (EVT) and inhibits the differentiation into ST [30].

Variations in oxygen levels in the placenta disturb the function, dynamics and integrity of the placental mitochondria. At 9 weeks of gestation, exposure of ST to $21 \%$ oxygen significantly deteriorates the mitochondrial integrity resulting in swollen mitochondria displaying irregular shapes and degeneration of their cristae. Conversely, when maintained at low oxygen tension, the ST mitochondria preserve their regular shape and condensed state with clearly defined cristae [31]. Although ST contains abundant mitochondria [31], the expression of antioxidant enzymes copper- and zinc-containing superoxide dismutase $(\mathrm{Cu} /$ ZnSOD) [32] and catalase [33] are scarcely detected by immunohistochemistry. In contrast, CT show high expression of these antioxidant enzymes [32, 33]. These striking differences in oxygen sensitivity suggest that ST might be physiologically protected for low oxygen tensions in vivo. However, a sudden burst of oxygen bioavailability would lead to increased vulnerability to oxidative stress. From the bioenergetics perspective, an increased vulnerability to oxygen availability in an environment of low oxygen may diminish the reliance of ST on mitochondria to sustain metabolic processes driven by mitochondria.

As pregnancy progresses, there is a continuous differentiation of CT to multinuclear ST which allows the formation of the outer layer of the placental villi. This process of differentiation relies on changes in mitochondrial energy production and signalling interactions $[34,35]$. A significant shift in energy metabolism precedes trophoblast fusion in CT differentiation to ST, including increased lactate production with enhanced anaerobic pathways [36] and lower antioxidant capacity [37] (Fig. 2). 
Fig. 2 Proposed mechanisms of cellular bioenergetics in cytotrophoblasts at early and late stages of pregnancy. Cat, catalase; MnSOD, manganese superoxide dismutase

\section{Cytotrophoblasts}

Early pregnancy

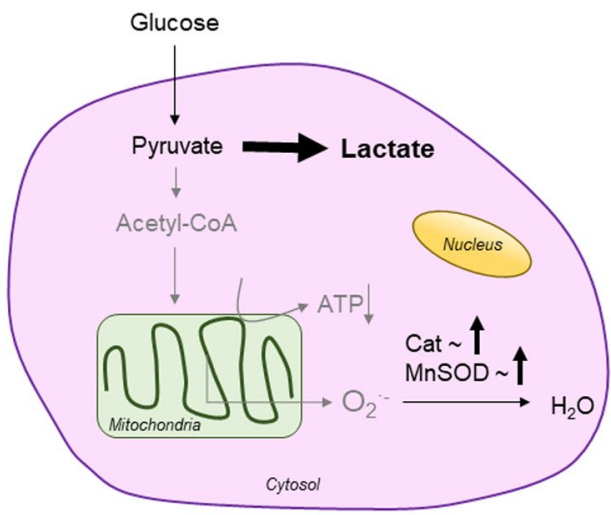

Late pregnancy

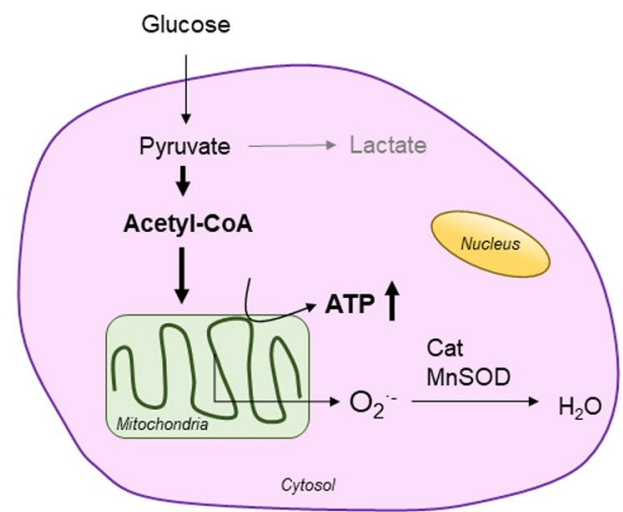

So far, several studies have put in evidence that CT and ST display strong differences in the structure and function of their mitochondria. However, our understanding of the role of mitochondria to sustain the energetic demands of EVT is limited. In the attempt to better understand the importance of mitochondria in EVT metabolism, a study has shown that the well-established immortalised EVT cell line (named HTR-8/SVneo) are resistant to apoptosis when exposed to low oxygen environment [38]. Interestingly, when cultured in normal oxygen tension, the EVT show an increased reliance on glycolytic pathways and suppressed mitochondrial reserve capacity. The EVT displays a highly glycolytic metabolism and therefore, are less sensitive to mitochondrial impairments associated with anti-angiogenic factor signalling [39].

Nevertheless, because of the variations in oxygen bioavailability, ROS are produced. However, these molecules have demonstrated to play important physiological signalling roles in early stages of gestation. For example, ROS triggers vascular endothelial growth factor signalling cascade and activates glucose transporters promoting the process of angiogenesis [40]. Although several studies suggest that ST and EVT are less reliant on mitochondrial function for energetic purposes, their mitochondrial machinery is fully capable of the generation of mtROS. Consequently, the role of mitochondria in the early stages of pregnancy might be mainly focused on mtROS production to promote cell signalling pathways and angiogenesis, allowing foetal growth and development.

These observations suggest that early in pregnancy, instead of exhibiting a crucial role in the generation of energy, mitochondria might be responsible for signalling interactions that could result in successful placental adaptations to stress (i.e. low oxygen, nutritional deprivation).

\section{Late pregnancy: role of placental mitochondria}

Several studies have identified the response of term placental trophoblasts to physiological and pathological stimuli. Nevertheless, the morphological structure and functionality of isolated term trophoblasts do not resemble the nature of trophoblasts at the early stages of pregnancy. Currently, the vast majority of trophoblast physiology research, although elegantly executed, employ term trophoblasts [41-43]. Considering that the placenta is discarded after birth as waste, probably the easiest approach to study placental function is utilizing term placental cell isolation and ex vivo studies.

During the last trimester of gestation, the layer of CT progressively disappears [44], the population of EVT is partially replaced by fibrinoid structures and at term, only a thin layer of ST covers the chorionic villi $[45,46]$. Several reports suggest that ST are mainly responsible for the metabolic activity of the maternal-foetal unit, as they are in intimate contact with the maternal blood. However, throughout gestation, CT are responsible for re-generating the layer of ST, which suggests that these trophoblasts might possess higher metabolic requirements. Likewise, CT highly expresses genes involved in the regulation of lipid uptake and metabolism [46] and displays higher glycolytic and mitochondrial activity in comparison to the differentiated term ST [41].

Studies evaluating the mitochondrial dynamics associated with the differentiation of term CT to ST have evidenced fragmentation of the mitochondrial network resulting in clear differences in the mitochondrial structure of term trophoblasts populations [41]. Term CT mitochondria are relatively larger with lamellar cristae whereas ST mitochondria are smaller, dense and with vesicular cristae [28, $47,48]$. This structural dissimilarity has been related to defective dimerization of mitochondrial complex V (ATP 
synthase) in ST [35]. Consistent with these structural differences, proteomic analysis in isolated term placental mitochondria demonstrated a differential regulation of 651 proteins with 29 of those being statistically different between ST and CT. Twenty-four of these proteins, including ATP synthase subunits $\alpha$ and $\beta$, superoxide dismutase and phosphoenolpyruvate carboxykinase were downregulated in ST whereas only five proteins were upregulated [49]. These variations imply that term trophoblast subpopulations; e.g. CT and ST may possess a distinguishable and unique metabolic phenotype. Supporting this assumption, studies using real-time bioenergetic assays have shown that CT display significantly higher levels of basal, ATP coupling and nonmitochondrial oxygen consumption rates when compared to ST, with no significant change in maximal respiration and reserve respiratory capacity [42]. Besides, it has been shown that the generation of ATP is increased in CT in comparison to subpopulations of ST [43]. Together, these observations suggest that term CT exhibit higher mitochondrial activity than ST. From the metabolic point of view, term CT displays different features than ST that may allow us to distinguish both trophoblasts subpopulations.

The role of placental mtROS in modulating cell signalling processes has been also addressed in trophoblast-like cells. Studies by Walker et al. using BeWo trophoblasts have identified that exposure to rotenone (mitochondrial complex I inhibitor) resulted in the generation of mtROS, reduced cellular fission and increased mitochondrial fragmentation, determined by decreased expression of mitochondrial fusion regulating proteins: mitofusin 2 (MFN2) and optic atrophy protein 1 (OPA1) and increased the expression of fission regulating protein dynamin-related protein 1 (DPR1) in differentiated and undifferentiated BeWo cells. Rescue experiments using pre-treatment with antioxidant $\mathrm{N}$-acetyl cysteine showed normalisation of MFN2 and OPA1 and partial restoration of DPR1 mRNA expression. These observations highlight the importance of mitochondrially-derived ROS in sustaining the mitochondrial structure and function of placental cells [50].

\section{Apoptosis in pregnancy}

Apoptotic cell death is a dynamic process by which dysfunctional cells are removed to maintain normal tissue function. It can be initiated through the mitochondria via the intrinsic pathway, in response to cellular stressors such as DNA damage [51]. The process is activated by the tumour suppressor protein, p53 which leads to transactivation of the proapoptotic Bcl-2 family [52]. Cytochrome c binds to apoptosis protease activation factor-1 resulting in oligomerisation and apoptosome formation [53]. The apoptosome facilitates caspase activation, specifically the recruitment of caspase 9 which activates caspase 3 and caspase 7, leading to immunosilent cleavage of unwanted cells.

Programmed cell death is important in normal pregnancy for processes including implantation and healthy development of the placenta. A study by Galan et al. showed that in the preattachment phase of implantation, the developing blastocyst averts apoptosis from human endometrial epithelial cells in order to adhere to the endometrium. This was indicated by a reduction in human endometrial epithelial cells apoptotic cells (35.2\%) compared to $48.8 \%$ for human endometrial epithelial cells cultured without the blastocyst. However, this study showed a considerable increase in paracrine apoptosis after adhesion which suggested that the regulation of apoptosis is a key process at early stages of pregnancy [54]. The role of apoptosis in pregnancy has shown that the development of normal pregnancies is associated to an increased rate of maternal peripheral blood apoptosis [55]. However, in terms of pregnancy, it has been shown that pregnancy itself is linked to a reduced rate of neutrophil apoptosis, in comparison to non-pregnant women, suggesting an explanation for the neutrophilia evidenced in normal pregnancies [56]. In terms of placental apoptosis, studies show that apoptosis increases through gestation and significantly accelerates at term [57]. Interestingly, increased levels of placental apoptosis have been identified in several pregnancy pathologies [56], including preeclampsia [58, 59] and IUGR [60, 61]. However, the molecular mechanisms associating exaggerated apoptosis with pregnancy complication remains unclear.

\section{Mitochondrial adaptations through pregnancy}

\section{Cardiovascular system}

Mitochondria consist of about $30 \%$ of the volume of cardiomyocytes and accounts for the bioenergetic homeostasis of the heart [62]. Some of the most important pregnancyrelated maternal adaptations occur in the cardiovascular system. Those maternal hemodynamic changes of pregnancy allow increased blood flow to various organs to meet energetics demands [63, 64], leading to vasodilation of the systemic vasculature, increased cardiac mass ( 50\%), increased cardiac output ( $20-50 \%$ ) resulting in increased energetic demands [65] and by the end of the first trimester of pregnancy a $50 \%$ increase of the glomerular filtration rates in kidneys [66, 67].

Although pregnancy requires a remarkable adaptation of the cardiovascular system to provide blood and metabolites to maternal organs and the foetal-placental unit, only a few studies in humans describe the metabolic adaptations of the heart during a normal pregnancy. Interestingly, during 
pregnancy, cardiac mitochondria can adapt to energetic challenges by increasing the rates of mitochondrial substrates utilisation. In this regard, studies in rats have shown that the rates of glucose utilisation decrease 7-fold as the pregnancy progresses while rates of fatty acid and ketone bodies utilisation increase by approximately 2.5 -fold and 6 -fold, respectively [68]. These differences in substrate preference may imply that cardiac mitochondrial metabolic adaptations are an important hallmark in the progression of normal pregnancies. This evidence suggests that early pregnancycardiac metabolism is mainly glucose-driven while towards later stages of gestation, mitochondria appear to play a key role in supporting the bioenergetic homeostasis in the heart.

Maternal metabolic impairments in gestational diabetes and obesity, increase the risk of the offspring to develop heart disease later in life [69]. Studies in neonatal rat cardiomyocytes showed that offspring from normal diet-exposed dams have highly dynamic mitochondria while diabetes or high-fat diet-exposed rats resulted in offspring's neonatal cardiomyocytes with shorter and wider structures along with defective gene expression of mitochondrial fusion regulating proteins: mitofusin 1 (MFN1), MFN2, OPA1 and pro-fission DRP1, mitochondrial fission regulating proteins: mitochondrial fission factor (MFF) and mitochondrial fission process 1 (MTFP1). Interestingly, these differences are influenced by foetal sex [70]. These observations infer that those cardiac mitochondrial perturbations arising in metabolically impaired pregnancies, may be involved in the onset of cardiovascular disease in the offspring at later stages of their life.

\section{Renal system}

Several pregnancy pathological complications and co-morbidities are associated with kidney-related impairments [71]. Studies by Popkov et al. showed that pregnancy enhances the mitochondrial membrane potential in renal isolated mitochondria in a model of renal ischaemia/reperfusion injury in rats [72]. In vivo models of preeclampsia have shown an association with excessive mtROS production and pathological outcomes. The reduced uteroplacental perfusion (RUPP) model established in rats showed that ischaemia insults impair the renal mitochondrial function by reducing the expression of mitochondrial complexes I and II, suppression of mitochondrial respiratory parameters [73] exacerbated production of mtROS [74]. Also, a model of hypertension in pregnancy in rats exposed to autoantibodies to the angiotensin II type 1 receptor, evidenced increased production of $\mathrm{H}_{2} \mathrm{O}_{2}$ as an indicator of oxidative stress [75]. In general, these studies are supportive of the existence of oxidative stress in renal tissue from complicated pregnancies and suggest that modulation of the oxidative damage in the kidney may be of therapeutic interest when managing these disorders.

\section{Skeletal muscle}

The skeletal muscle accounts for approximately $50 \%$ of the body mass and its energetic requirements rely on glucose and fatty acid utilisation [76]. Although there are numerous studies addressing the role of mitochondria in human skeletal muscle during excersice, our understanding of the role of mitochondria to sustain skeletal muscle function in phases of human reproduction is not yet clear. The effects of low maternal energy diets have been studied in pigs, showing that nutritional deprivation reduces the mitochondrial DNA (mtDNA) copy number, citrate synthase and $\mathrm{NAD}^{+}$-to-NADH ratio in their offspring's skeletal muscle compared to standard energy diet offspring. This restrictive energetic diet caused a reduction in the transcription of mitochondrial biogenesis genes, PPARG Coactivator 1 Alpha (PPARGC1- $\alpha$ ) and Sirtuin 1 and impaired the antioxidant defences expressed by reduced SOD and catalase mRNA and protein expression in foetal skeletal tissue [77]. The effects of maternal nutritional restriction have been associated with the onset of several pregnancy-related disorders [78] and the programming of foetal developmental alterations [79]. Therefore, restrained maternal nutrition might seriously alter the skeletal muscle homeostasis in the offspring and these events are likely to be influenced by defective mitochondrial biogenesis signals reprogrammed in the offspring. Nevertheless, most studies attempting to reveal the role of mitochondrial dysfunction in skeletal muscle during pregnancy, have been performed using animal models, requiring a more attentive interpretation of those implications for human pregnancy.

\section{Mitochondrial dysfunction in pregnancy-related disorders}

The study of the dysregulation in mtROS production in pregnancy-associated complications such as; preeclampsia, IUGR, gestational diabetes and pre-term birth is a hot topic of research in the field of reproductive biology. There is accumulative evidence demonstrating the effectiveness of mitochondrially targeted therapeutics to modulate the redox balance in a variety of these disorders. Hence, this section summarises key mitochondrial disturbances observed in pathological pregnancy outcomes including studies in placental, vascular and cardiovascular tissues and highlights the potential benefit of drugs with recognised effects on mitochondria to potentially manage preeclampsia.

\section{Preeclampsia}

Preeclampsia is a disorder of pregnancy arising from the $20^{\text {th }}$ week of gestation, clinically characterised by newly-onset 
hypertension and proteinuria [80]. From the molecular point of view, preeclampsia is associated with the upregulation of circulating levels of anti-angiogenic factors soluble Flt-1 (sFlt-1) and soluble endoglin [81] that might account for maternal vascular dysfunction and oxidative stress described in preeclampsia [78].

The role of the placental mitochondria in preeclampsia has been well studied. However, there are inconsistencies in results showing dramatic variations in terms of mitochondrial structure, content and function. Human studies have shown that gene expression of mitochondrial dynamics proteins, OPA1, fission 1 (FIS1), MFN1 and MFN2 are impaired in preeclamptic term placentas $[82,83]$. Conversely, others have shown elevated expression in markers of mitochondrial fission; MFN1 and MFN2 in preeclampsia [84]. The placental mitochondrial content and mitochondrial biogenesis signals, important for the preservation of tissue function and metabolic activity, have also shown some inconsistencies [85]. In this regard, while some have reported decreased OXPHOS activity [86] and reduced expression of mitochondrial ETC complexes in preeclampsia [87-89], a recent report demonstrate otherwise [82]. One potential explanation for these diaparities can be attributed to the gestational age of preeclampsia onset. For example, studies by Holland et al. showed that pre-term preeclamptic placental display a reduction in mitochodnrial antioxidant activity (SOD activity in mitochondrial content) when compared to normotensive pre-term, term normotensive and term preeclamptic counterparts [82]. Another potential explanation can be attributed to the severity of preeclampsia included in those studies. In this regard, studies by Zhou et al. focused on term preeclamptic placentas, including severe preeclapmsia patients [84]. As these variables on preeclampsia development (gestational age and severity) can be crucial for diagnose and management [90,91], a vigilous interpretation of results is suggested in order to better understand the role of mitochondria in the onset of this complication.

Others have reported evidence of dysregulation in the mitochondrial integrity and function in models displaying preeclampsia-like signs. Several mice models mimicking the preeclampsia condition induced by treatment with Nw-nitro-L-arginine-methyl ester (L-NAME, nitric oxide synthase inhibitor), lipopolysaccharide, $\beta 2$ glycoprotein I [92], sFlt-1-injected mice [93] and STOX1 transgenic mouse [94], have shown similar impairments in the structure of trophoblast mitochondria exhibiting increased swelling and cristae disappearance. Similarly, the expression of mtROS detoxifying enzymes, including the mitochondrial uncoupling protein 1 (UCP-1) and superoxide dismutase 2 (SOD2) are reduced in models of preeclampsia [74, 94].

As preeclampsia originates from the second trimester of pregnancy, studying term placental tissue might not be a reliable approach to either study molecular mechanisms of the disorder or to evaluate effective therapeutics to prevent it. Given that preeclampsia is a maternal complication, mostly affecting the vasculature of the mothers, in vitro studies using endothelial cells have provided new insights into the contribution of dysfunctional mitochondria in vascular dysfunction. Exposure of endothelial cells to plasma from preeclamptic women have shown to significantly increase the production of mtROS [39, 73, 95] and to suppress the basal and maximal respiratory capacity $[39,95]$. The expression of mitochondrial respiratory complexes, citrate synthase and fatty acid oxidation is reduced in human umbilical vein endothelial cells (HUVEC) isolated from preeclamptic pregnancies [96]. Studies in rats emulating the preeclampsialike disorder have also supported the role of mitochondria in the production of mtROS and suppression of OXPHOS in renal tissue [73, 74, 97]. Likewise, analysis of blood samples from preeclamptic and uncomplicated pregnancies showed increased superoxide generation that negatively correlates with microvascular endothelial function in preeclampsia [12].

\section{Intrauterine growth restriction (IUGR)}

IUGR is a pregnancy-specific disorder characterised by a reduced foetal growth rate in comparison to the expected growth at a specific stage of gestational development [98]. The molecular features of IUGR share a common placental phenotype with other hypertensive disorders of pregnancy, characterised by "placental insufficiency" at the early stages of pregnancy [99]. The role of mitochondrial dysfunction in IUGR pathogenesis is not yet clear. However, there is evidence suggesting that mitochondrial impairments are associated with this complication [100].

Studies in placental tissue from IUGR patients showed an increased mitochondrial content (measured as mtDNA) in this group in comparison to normal pregnancies [99, 101]. Interestingly, the content of mitochondria in isolated placental CT is lower in the IUGR group [99]. Similarly, mRNA levels of mitochondrial biogenesis regulator, nuclear respiratory factor 1 (NRF1) is increased in placentas from IUGR but reduced in isolated CT. The expression and activity of mitochondrial complexes subunits are also reduced in IUGR [99, 102]. Nevertheless, controversial results have been reported showing increased OXPHOS efficiency in comparison to control [99] while others have described the mitochondrial activity to be reduced [102]. A potential explanation for these contrasting results may be associated to the complexity of the placental structure and multiple cell types composing the placenta. For example, cells composing the maternal section include trophoblasts, stromal and fibroblast-like cells and macrophages. In contrast, the foetal section is composed by a layer of ephitelial cells resting over a layer 
of connective tissue associated with foetal blood vessels [103]. Therefore, results found in whole placental tissue could be related to cell types other than CT.

To explain these variations in mitochondrial content and activity, Jones et al. suggested that these might result as a metabolic compensatory mechanism. In this regard, placentas from IUGR pregnancies have shown to express increased mRNA levels of glycolysis-regulatory gene PDK1 (Pyruvate Dehydrogenase Kinase 1) [104]. These exciting results suggest that other cell types, including ST, mesenchymal cells and fibroblasts might contain a significant number of mitochondria and may account for the increased content observed in whole placental tissue from IUGR. Knowing that in normal pregnancies the mitochondrial content and structure of ST tend to reduce while pregnancy progresses, these observations suggest that IUGR may accompany a dysregulation in placental mitochondrial adaptations along with modulation of less efficient pathways such as glycolysis, possibly to sustain the enhanced energetic requirements exert by the foetus.

Plasma mediators in IUGR pregnancies have been shown to reduce endothelial cell viability and to promote intracellular ROS production in vitro. Electron microscopy studies have revealed that HUVEC isolated from IUGR pregnancies evidence cellular abnormalities including mitochondrial swelling, enlarged intermembrane spaces and disrupted cristae [105]. These observations reveal a similar pattern with preeclampsia-induced mitochondrial dysfunction in endothelial cells, suggesting a common pathway in the pathophysiology of these disorders. In a rat model of IUGR, it was evidenced a reduction in pyruvate, succinate and $\alpha$-ketoglutarate oxidation rates along with increased manganese superoxide dismutase (MnSOD) protein levels [106]. IUGR is also associated with skeletal muscle perturbations linked to defective glucose homeostasis and reduced muscle respiration [100].

Other evidence suggests that mitochondrial dysfunction is a mechanism of foetal metabolic programming in offspring from IUGR. In a model of IUGR established in pigs, it was shown that IUGR offspring fed with a highfat diet exhibit reduced activity of lactate dehydrogenase (LDH) and glucose-6-phosphate dehydrogenase (G6PD) accompanied by suppressed succinate and glutamateinduced OXPHOS activity, reduced mitochondrial contents and downregulation of mRNA expression of genes involved in mitochondrial biogenesis in skeletal muscle [107]. Similarly, a model of IUGR in mice established by maternal undernutrition, affected the cardiac bioenergetics by suppressing fatty acid oxidation [108], suggesting a greater susceptibility of IUGR offspring to dysregulation in cardiac energetic balance.

\section{Gestational diabetes (GDM)}

The first detection of hyperglycaemia during pregnancy is classified as "diabetes mellitus in pregnancy" or "gestational diabetes (GDM) mellitus" by the World Health Organization (WHO) [109]. In some circumstances, maternal tissues fail to sustain the metabolic adaptations required for pregnancy resulting in complications such as GDM [110, 111]. Although the molecular events leading to GDM are still not well understood, the dysregulation of mitochondrial substrate oxidation has been proposed to play a role in GDM.

Studies in term trophoblasts from women with GDM showed downregulation of mitochondrial biogenesis modulator, PGC1- $\alpha$ (peroxisome proliferator-activated receptor gamma coactivator 1-alpha) and suppressed parameters of mitochondrial function along with a two-fold increase in glucose transporter GLUT-1 expression [112]. Mitochondrial dynamics are also impaired in GDM showing pro-fusion features with elevated OPA1 and DRP1 expression [113]. GDM is also linked to increased placental lipid peroxidation and oxidised proteins (carbonyls) [114]. In the maternal skeletal muscle, GDM has also shown to impair the expression of mitochondrial complex I [115]. These observations propose that the metabolic perturbations exerted by GDM in the placental tissue may result in the inability of maternal tissues to adapt to the metabolic demands.

When a healthy diet along with exercise is not enough to regulate maternal glucose levels, drugs such as insulin and metformin are indicated to manage GDM [116]. However, metformin is known to suppress the activity of mitochondrial complex I and to prevent complex I-induced mtROS generation [117]. As the American College of Obstetricians and Gynaecologists (ACOG) and the National Institute for Health and Care Excellence (NICE) guidelines recommend, metformin represents the first line of choice for the management of GDM [118, 119]. Therefore, our interpretation of studies evaluating the function of mitochondria using tissues or cells derived from GDM patients treated with metformin should be cautious.

\section{Targeting mitochondrial metabolism in the management of preeclampsia}

Antioxidant therapies have largely demonstrated to fail in the management of preeclampsia. One possible explication relies on the potential inability of these drugs to reach and accumulate in relevant cellular compartments, such as the mitochondria. In the past decades, compounds targeting the mitochondria have gained great interest in their abilities to moderate mtROS generation and cellular bioenergetics in a myriad of pathological disorders [120]. 
Some unique features on the mitochondrial inner membrane composition and function, such as its high transmembrane potential and particular phospholipid composition allowed the targeting of mitochondria [121]. Approaches for directing drugs for delivery and accumulation within the mitochondria include links to a lipophilic cation moieties such as triphenylphosphonium $\left(\mathrm{TPP}^{+}\right)$, cardiolipin and heterocyclic aromatic cations [120].

Emerging research describes mitochondrial dysfunction and oxidative stress as molecular hallmarks of preeclampsia. Therefore, recent efforts to elucidate effective therapies to manage this disorder have focused on the mitochondria. Different drugs with effects on mitochondria (either specifically targeted or not) have been evaluated in models of preeclampsia. A list of compounds with recognised effects on mitochondrial function targeting the restoration of mitochondrial function in vitro, in vivo and clinical trials for the management of preeclampsia are described in Table 1.

\section{Metformin}

Metformin, although not a mitochondrial-targeted drug, has proven abilities to cause unspecific inhibition of the mitochondrial complex I [117]. For that reason, the use of metformin for treating and or preventing preeclampsia has been included in this section.

Studies using villous $\mathrm{CT}$, preterm preeclamptic villous explants and primary endothelial cells, have shown that metformin alone or in combination with other drugs, significantly abrogates sFlt-1 and soluble endoglin production [122-124]. As previously described in section "preeclampsia", sFlt-1 and soluble endoglin are anti-angiogenic factors implicated in the pathogenesis of preeclampsia. In a model of preeclampsia in mice fed with a high-fat diet, the use of metformin has also shown to improve maternal blood pressure and foetal outcomes [125].

A phase II trial study (currently undergoing) protocol was recently published. This study aims to evaluate the efficacy of metformin to treat preterm preeclampsia (trial number PACTR201608001752102) [126]. Nonetheless, previous studies, although not focused on a cohort of preeclampsia patients, have provided insights into the potential effects of metformin to prevent this disorder. Nevertheless, the approach of metformin for managing preeclampsia should be cautions as two clinical trials performed in the UK focused on obese and diabetic cohorts showed contradictive results regarding the effectiveness of metformin on the risk of preeclampsia [127].

\section{AP39}

The novel hydrogen sulfide $\left(\mathrm{H}_{2} \mathrm{~S}\right)$ donor, AP39 consists of an $\mathrm{H}_{2} \mathrm{~S}$-donating moiety (dithiolethione) coupled to a $\mathrm{TPP}^{+}$motif by an aliphatic linker targeting the release of $\mathrm{H}_{2} \mathrm{~S}$ to the mitochondria (Fig. 3). The effectiveness of AP39 to promote the mitochondrial function has been tested in endothelial cells. This study showed that AP39 exerts cytoprotective effects and maintains the mtDNA integrity while improving the mitochondrial bioenergetics in endothelial cells exposed to high glucose levels [128]. Regarding the potential protective effect of AP39 on the placenta, Covarrubias et al. reported that AP39 significantly prevents sFlt-1 release, abrogates the generation of mtROS and enhances cytochrome c activity in isolated human primary trophoblasts exposed to hypoxia [129].

\section{Mito-Tempo and MitoQ}

Mito-Tempo is a mitochondrial-targeted antioxidant compound consisting of the antioxidant piperidine nitroxide, superoxide dismutase mimetic (Tempo), linked to $\mathrm{TPP}^{+}$[130]. MitoQ consists of an antioxidant compound (quinone) linked to $\mathrm{TPP}^{+}[131,132]$ (Fig. 3). In a study in vitro, McCarthy et al. assessed the ability of mito-Tempo to protect against preeclampsia plasma mediators-induced mtROS generation in HUVEC. In this study, mito-Tempo also showed protective effects against $\mathrm{H}_{2} \mathrm{O}_{2}$-induced cell death [95].

In another study, both mitochondrial-targeted antioxidants suppressed the production of mtROS in HUVEC exposed to serum collected from RUPP animals. In this same report, the authors showed in an in vivo RUPP model that treatment with mito-Tempo and mitoQ reduce the mean blood pressure and improve pup and placental weight. However, mito-Tempo but not mitoQ improved litter size [73]. Similar reports have been provided by Yang et al. showing the effectiveness of mitoQ in alleviating preeclampsia-like signs in a RUPP model established in mice [133]. Studies in vitro, have shown that mitoQ partially prevents the production of ROS from placental explants exposed to monoclonal antiphospholipid antibodies [134].

\section{Coenzyme Q10}

Coenzyme Q10 or ubiquinone is a lipid-soluble antioxidant that participates in the electron transfer from complexes I and II to complex III in the mitochondria [135]. The effectiveness of coenzyme Q10 to prevent the risk of preeclampsia was investigated in a double-blind randomised study. The study showed a significant reduction $(p=0.035)$ in the rate of preeclampsia in the coenzyme Q10 group in comparison to the placebo group [136]. Alongside, recent reports by Xu et al. have shown that coenzyme Q10 prevents preeclampsialike signs in L-NAME treated rats [137]. 


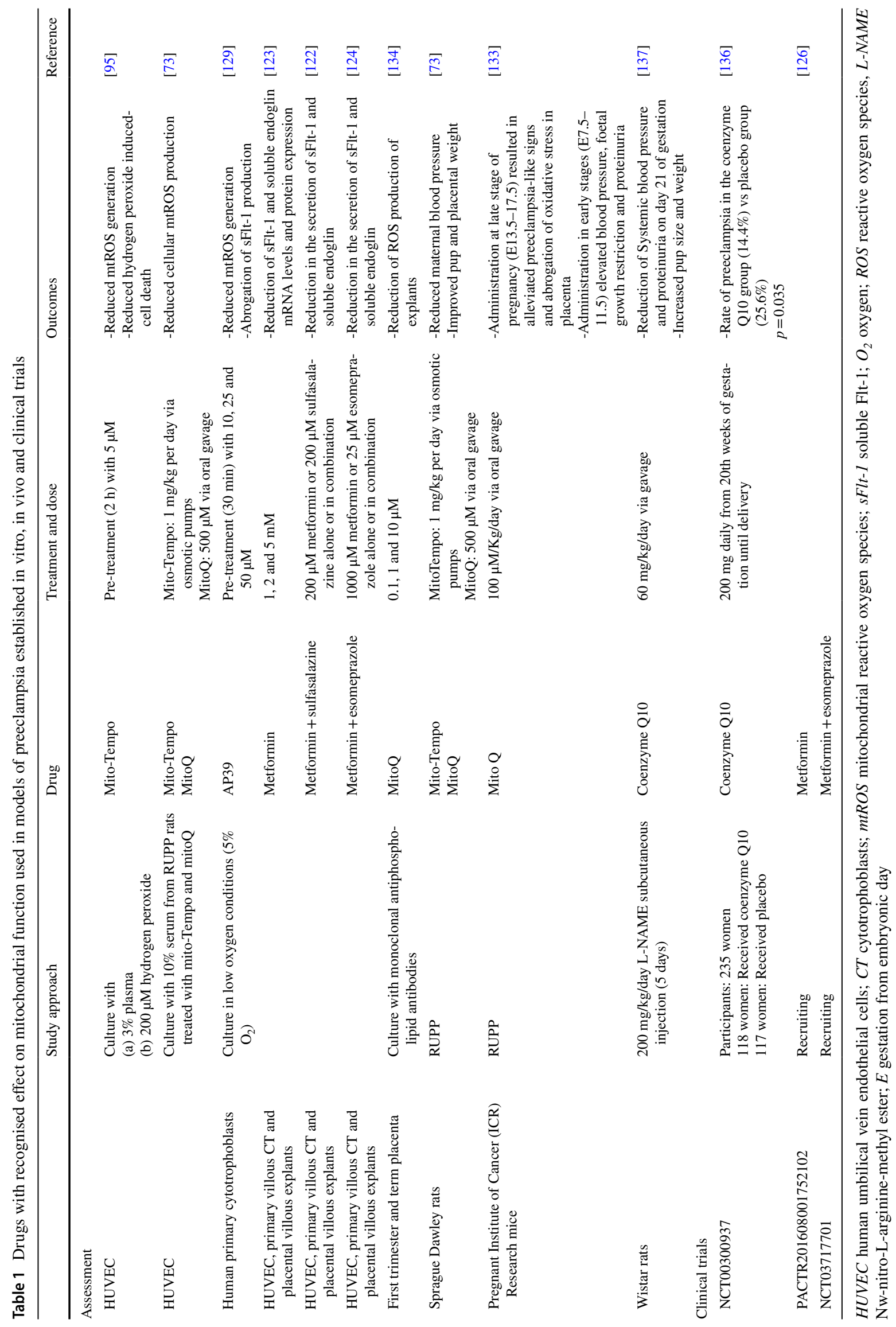




\section{Conclusion}

The role of mitochondria in pregnancy and its related complications have mainly focused on understanding the structural adaptations occurring in the mitochondria of subpopulations of placental trophoblasts at term. However, little is known about the behaviour of these organelles at the early stages of gestation. Through pregnancy, trophoblasts display structural and functional adaptations in their mitochondria, resulting in distinguished differences between subpopulations of trophoblast at term. These metabolic fingerprints might be accountable for the distinct function of trophoblasts to support and sustain the pregnancy. As subpopulations of term trophoblasts' mitochondria behave differently, appropriate methods to study and compare the function of trophoblasts are required.

The onset of a myriad of pathological pregnancy outcomes is associated with oxidative stress arising at the early stages of pregnancy. Still, functional studies are mainly performed in isolated term trophoblasts and this approach is not representative of the developmental structures and characteristics of early trophoblasts. These limitations have hindered our understanding of the bioenergetics adaptations and redox systems at early stages and therefore have delayed the exploration of appropriate targets for effective treatments.

Many pregnancy disorders have been linked to placental insufficiency. However, it is equally important to explore the responses of the maternal endothelium and to recognise the capabilities of maternal tissues to sustain energetic requirements during pregnancy. In other scenarios, early metabolic perturbations are implicated in the onset of disease. In pregnancy, failure to adapt to increased energetics demands might lead to dysfunction in key maternal tissues, leading to adverse outcomes. Mitochondria are crucial organelles supporting energy production not only in the placenta but in the endothelium. Therefore, targeting mitochondria is an attractive approach to tackle a variety of oxidative stress-related disorders. Although its exploration is still novel, mitochondrial-targeted antioxidants have provided new insights for the effective management of preeclampsia in proof of concept studies. Recently, drugs such as metformin and coenzyme Q10 that although are not targeted to the mitochondria, are capable to exert mitochondrial effects and have been proposed to treat preeclampsia in clinical trials. It is still not clear whether mitochondrial-targeted drugs can prevent preeclampsia and more results are needed to clarify if the selective delivery of antioxidants and metabolic modulators to the mitochondria, are effective to prevent preeclampsia-like symptoms.

Author contributions LSA designed the review idea, wrote the manuscript and draw all figures and tables. SN edited and prepared revisions.
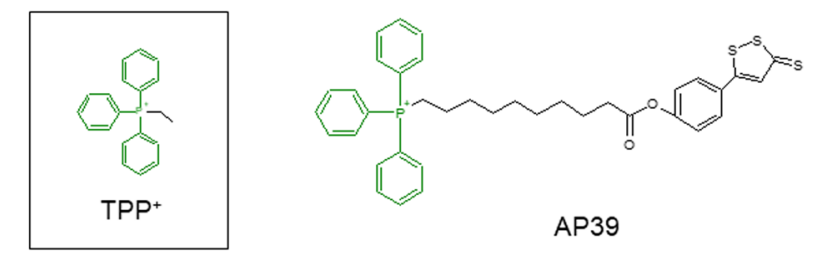

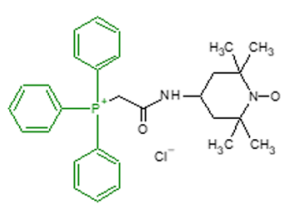

Mito-Tempo

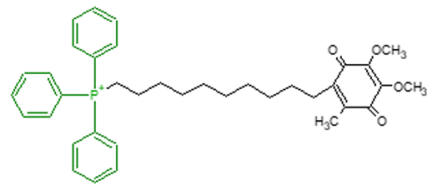

Mito-Q
Fig. 3 Structure of mitochondrial-targeted AP39, Mito-Tempo and Mito-Q. TPP ${ }^{+}$, triphenylphosphonium

Funding There was no funding support for this work.

\section{Declarations}

Conflict of interest The authors have no conflict of interest to declare.

Open Access This article is licensed under a Creative Commons Attribution 4.0 International License, which permits use, sharing, adaptation, distribution and reproduction in any medium or format, as long as you give appropriate credit to the original author(s) and the source, provide a link to the Creative Commons licence, and indicate if changes were made. The images or other third party material in this article are included in the article's Creative Commons licence, unless indicated otherwise in a credit line to the material. If material is not included in the article's Creative Commons licence and your intended use is not permitted by statutory regulation or exceeds the permitted use, you will need to obtain permission directly from the copyright holder. To view a copy of this licence, visit http://creativecommons.org/licenses/by/4.0/.

\section{References}

1. Chandel NS (2014) Mitochondria as signaling organelles. BMC Biol 12:34. https://doi.org/10.1186/1741-7007-12-34

2. Zeng Z, Liu F, Li S (2017) Metabolic adaptations in pregnancy: a review. Ann Nutr Metab 70(1):59-65. https://doi.org/10.1159/ 000459633

3. Villar J, Cogswell M, Kestler E, Castillo P, Menendez R, Repke JT (1992) Effect of fat and fat-free mass deposition during pregnancy on birth weight. Am J Obstet Gynecol 167(5):1344-1352. https://doi.org/10.1016/s0002-9378(11)91714-1

4. Herrera E, Desoye G (2016) Maternal and fetal lipid metabolism under normal and gestational diabetic conditions. Horm Mol Biol Clin Investig 26(2):109-127. https://doi.org/10.1515/ hmbci-2015-0025

5. Lain KY, Catalano PM (2007) Metabolic changes in pregnancy. Clin Obstet Gynecol 50(4):938-948. https://doi.org/10.1097/ GRF.0b013e31815a5494

6. Jiang F, Zhang Y, Dusting GJ (2011) NADPH oxidase-mediated redox signaling: roles in cellular stress response, stress tolerance, and tissue repair. Pharmacol Rev 63(1):218-242. https://doi.org/ 10.1124/pr.110.002980 
7. Sena LA, Chandel NS (2012) Physiological roles of mitochondrial reactive oxygen species. Mol Cell 48(2):158-167. https:// doi.org/10.1016/j.molcel.2012.09.025

8. Finkel T (2011) Signal transduction by reactive oxygen species. J Cell Biol 194(1):7-15. https://doi.org/10.1083/jcb.201102095

9. Betteridge DJ (2000) What is oxidative stress? Metabolism 49(2 Suppl 1):3-8. https://doi.org/10.1016/s0026-0495(00)80077-3

10. Schieber M, Chandel NS (2014) ROS function in redox signaling and oxidative stress. Curr Biol 24(10):R453-462. https://doi.org/ 10.1016/j.cub.2014.03.034

11. Mert I, Oruc AS, Yuksel S, Cakar ES, Buyukkagnici U, Karaer A, Danisman N (2012) Role of oxidative stress in preeclampsia and intrauterine growth restriction. J Obstet Gynaecol Res 38(4):658-664. https://doi.org/10.1111/j.1447-0756.2011. 01771.x

12. Mannaerts D, Faes E, Cos P, Briede JJ, Gyselaers W, Cornette J, Gorbanev Y, Bogaerts A, Spaanderman M, Van Craenenbroeck E, Jacquemyn Y (2018) Oxidative stress in healthy pregnancy and preeclampsia is linked to chronic inflammation, iron status and vascular function. PLoS ONE 13(9):e0202919. https://doi. org/10.1371/journal.pone.0202919

13. Li H, Yin Q, Li N, Ouyang Z, Zhong M (2016) Plasma markers of oxidative stress in patients with gestational diabetes mellitus in the second and third trimester. Obstet Gynecol Int. https://doi. org/10.1155/2016/3865454

14. Yiyenoglu OB, Ugur MG, Ozcan HC, Can G, Ozturk E, Balat O, Erel O (2014) Assessment of oxidative stress markers in recurrent pregnancy loss: a prospective study. Arch Gynecol Obstet 289(6):1337-1340. https://doi.org/10.1007/s00404-013-3113-4

15. Alberts B (2015) Molecular biology of the cell, 6th edn. Garland Science, New York

16. Wallace DC (2012) Mitochondria and cancer. Nat Rev Cancer 12(10):685-698. https://doi.org/10.1038/nrc3365

17. Martinez-Reyes I, Chandel NS (2020) Mitochondrial TCA cycle metabolites control physiology and disease. Nat Commun 11(1):102. https://doi.org/10.1038/s41467-019-13668-3

18. Wallace DC, Fan W, Procaccio V (2010) Mitochondrial energetics and therapeutics. Annu Rev Pathol 5:297-348. https://doi.org/ 10.1146/annurev.pathol.4.110807.092314

19. Bratic I, Trifunovic A (2010) Mitochondrial energy metabolism and ageing. Biochim Biophys Acta 1797(6-7):961-967. https:// doi.org/10.1016/j.bbabio.2010.01.004

20. Karaa A, Elsharkawi I, Clapp MA, Balcells C (2019) Effects of mitochondrial disease/dysfunction on pregnancy: a retrospective study. Mitochondrion 46:214-220. https://doi.org/10.1016/j. mito.2018.06.007

21. Motta PM, Nottola SA, Makabe S, Heyn R (2000) Mitochondrial morphology in human fetal and adult female germ cells. Hum Reprod 15(Suppl 2):129-147. https://doi.org/10.1093/humrep/ 15.suppl_2.129

22. Harvey AJ (2019) Mitochondria in early development: linking the microenvironment, metabolism and the epigenome. Reproduction 157(5):R159-R179. https://doi.org/10.1530/REP-18-0431

23. Santos TA, El Shourbagy S, St John JC (2006) Mitochondrial content reflects oocyte variability and fertilization outcome. Fertil Steril 85(3):584-591. https://doi.org/10.1016/j.fertnstert.2005. 09.017

24. Moren C, Hernandez S, Guitart-Mampel M, Garrabou G (2014) Mitochondrial toxicity in human pregnancy: an update on clinical and experimental approaches in the last 10 years. Int J Environ Res Public Health 11(9):9897-9918. https://doi.org/10.3390/ ijerph110909897

25. Harvey AJ, Kind KL, Thompson JG (2002) REDOX regulation of early embryo development. Reproduction 123(4):479-486. https://doi.org/10.1530/rep.0.1230479
26. Sharma RK, Agarwal A (2004) Role of reactive oxygen species in gynecologic diseases. Reprod Med Biol 3(4):177-199. https:// doi.org/10.1111/j.1447-0578.2004.00068.x

27. Kaufmann P, Black S, Huppertz B (2003) Endovascular trophoblast invasion: implications for the pathogenesis of intrauterine growth retardation and preeclampsia. Biol Reprod 69(1):1-7. https://doi.org/10.1095/biolreprod.102.014977

28. Fisher JJ, Bartho LA, Perkins AV, Holland OJ (2020) Placental mitochondria and reactive oxygen species in the physiology and pathophysiology of pregnancy. Clin Exp Pharmacol Physiol 47(1):176-184. https://doi.org/10.1111/1440-1681.13172

29. Rodesch F, Simon P, Donner C, Jauniaux E (1992) Oxygen measurements in endometrial and trophoblastic tissues during early pregnancy. Obstet Gynecol 80(2):283-285

30. Wakeland AK, Soncin F, Moretto-Zita M, Chang CW, Horii M, Pizzo D, Nelson KK, Laurent LC, Parast MM (2017) Hypoxia directs human extravillous trophoblast differentiation in a hypoxia-inducible factor-dependent manner. Am J Pathol 187(4):767-780. https://doi.org/10.1016/j.ajpath.2016.11.018

31. Watson AL, Skepper JN, Jauniaux E, Burton GJ (1998) Susceptibility of human placental syncytiotrophoblastic mitochondria to oxygen-mediated damage in relation to gestational age. J Clin Endocrinol Metab 83(5):1697-1705. https://doi.org/10.1210/ jcem.83.5.4830

32. Watson AL, Palmer ME, Jauniaux E, Burton GJ (1997) Variations in expression of copper/zinc superoxide dismutase in villous trophoblast of the human placenta with gestational age. Placenta 18(4):295-299. https://doi.org/10.1016/s0143-4004(97) 80064-1

33. Watson AL, Skepper JN, Jauniaux E, Burton GJ (1998) Changes in concentration, localization and activity of catalase within the human placenta during early gestation. Placenta 19(1):27-34 . https://doi.org/10.1016/s0143-4004(98)90095-9

34. Bax BE, Bloxam DL (1997) Energy metabolism and glycolysis in human placental trophoblast cells during differentiation. Biochim Biophys Acta 1319(2-3):283-292. https://doi.org/10.1016/ s0005-2728(96)00169-7

35. De Los Rios Castillo D, Zarco-Zavala M, Olvera-Sanchez S, Pardo JP, Juarez O, Martinez F, Mendoza-Hernandez G, GarciaTrejo JJ, Flores-Herrera O (2011) Atypical cristae morphology of human syncytiotrophoblast mitochondria: role for complex V. J Biol Chem 286(27):23911-23919. https://doi.org/10.1074/jbc. M111.252056

36. Poidatz D, Dos Santos E, Gronier H, Vialard F, Maury B, De Mazancourt P, Dieudonne MN (2015) Trophoblast syncytialisation necessitates mitochondrial function through estrogen-related receptor-gamma activation. Mol Hum Reprod 21(2):206-216. https://doi.org/10.1093/molehr/gau102

37. Xie Y, Zhou S, Jiang Z, Dai J, Puscheck EE, Lee I, Parker G, Huttemann M, Rappolee DA (2014) Hypoxic stress induces, but cannot sustain trophoblast stem cell differentiation to labyrinthine placenta due to mitochondrial insufficiency. Stem Cell Res 13(3 Pt A):478-491. https://doi.org/10.1016/j.scr.2014.07.007

38. Armant DR, Kilburn BA, Petkova A, Edwin SS, Duniec-Dmuchowski ZM, Edwards HJ, Romero R, Leach RE (2006) Human trophoblast survival at low oxygen concentrations requires metalloproteinase-mediated shedding of heparin-binding EGF-like growth factor. Development 133(4):751-759. https://doi.org/10. 1242/dev.02237

39. Sanchez-Aranguren LC, Espinosa-Gonzalez CT, GonzalezOrtiz LM, Sanabria-Barrera SM, Riano-Medina CE, Nunez AF, Ahmed A, Vasquez-Vivar J, Lopez M (2018) Soluble Fms-like tyrosine kinase-1 alters cellular metabolism and mitochondrial bioenergetics in preeclampsia. Front Physiol 9:83. https://doi.org/ 10.3389/fphys.2018.00083 
40. Al-Gubory KH, Fowler PA, Garrel C (2010) The roles of cellular reactive oxygen species, oxidative stress and antioxidants in pregnancy outcomes. Int J Biochem Cell Biol 42(10):1634-1650. https://doi.org/10.1016/j.biocel.2010.06.001

41. Kolahi KS, Valent AM, Thornburg KL (2017) Cytotrophoblast, not syncytiotrophoblast, dominates glycolysis and oxidative phosphorylation in human term placenta. Sci Rep 7:42941. https://doi.org/10.1038/srep42941

42. Maloyan A, Mele J, Muralimanohara B, Myatt L (2012) Measurement of mitochondrial respiration in trophoblast culture. Placenta 33(5):456-458. https://doi.org/10.1016/j.placenta.2012.01. 016

43. Fisher J, McKeating D, Pennell E, Cuffe J, Holland O, Perkins A (2019) Mitochondrial isolation, cryopreservation and preliminary biochemical characterisation from placental cytotrophoblast and syncytiotrophoblast. Placenta 82:1-4. https://doi.org/10.1016/j. placenta.2019.05.004

44. Benirschke K, Kaufmann P (1995) Pathology of the human placenta, 3rd edn. Springer, New York

45. Turco MY, Moffett A (2019) Development of the human placenta. Development. https://doi.org/10.1242/dev.163428

46. Kolahi K, Louey S, Varlamov O, Thornburg K (2016) Real-time tracking of BODIPY-C12 long-chain fatty acid in human term placenta reveals unique lipid dynamics in cytotrophoblast cells. PLoS ONE 11(4):e0153522. https://doi.org/10.1371/journal. pone. 0153522

47. Jones CJ, Fox H (1991) Ultrastructure of the normal human placenta. Electron Microsc Rev 4(1):129-178. https://doi.org/10. 1016/0892-0354(91)90019-9

48. Martinez F, Kiriakidou M, Strauss JF 3rd (1997) Structural and functional changes in mitochondria associated with trophoblast differentiation: methods to isolate enriched preparations of syncytiotrophoblast mitochondria. Endocrinology 138(5):21722183. https://doi.org/10.1210/endo.138.5.5133

49. Fisher JJ, McKeating DR, Cuffe JS, Bianco-Miotto T, Holland OJ, Perkins AV (2019) Proteomic analysis of placental mitochondria following trophoblast differentiation. Front Physiol 10:1536. https://doi.org/10.3389/fphys.2019.01536

50. Walker OS, Ragos R, Wong MK, Adam M, Cheung A, Raha $S$ (2020) Reactive oxygen species from mitochondria impacts trophoblast fusion and the production of endocrine hormones by syncytiotrophoblasts. PLoS ONE 15(2):e0229332. https://doi. org/10.1371/journal.pone.0229332

51. Straszewski-Chavez SL, Abrahams VM, Mor G (2005) The role of apoptosis in the regulation of trophoblast survival and differentiation during pregnancy. Endocr Rev 26(7):877-897. https:// doi.org/10.1210/er.2005-0003

52. Miyashita T, Reed JC (1995) Tumor suppressor p53 is a direct transcriptional activator of the human bax gene. Cell 80(2):293299. https://doi.org/10.1016/0092-8674(95)90412-3

53. Bratton SB, Salvesen GS (2010) Regulation of the Apaf-1-caspase-9 apoptosome. J Cell Sci 123(Pt 19):3209-3214. https://doi. org/10.1242/jcs.073643

54. Galan A, O'Connor JE, Valbuena D, Herrer R, Remohi J, Pampfer S, Pellicer A, Simon C (2000) The human blastocyst regulates endometrial epithelial apoptosis in embryonic adhesion. Biol Reprod 63(2):430-439. https://doi.org/10.1093/biolreprod/ 63.2 .430

55. Kolialexi A, Tsangaris GT, Antsaklis A, Tzortzatou F, Amentas C, Koratzis A, Mavrou A (2001) Apoptosis in maternal peripheral blood during pregnancy. Fetal Diagn Ther 16(1):32-37. https://doi.org/10.1159/000053877

56. von Dadelszen P, Watson RW, Noorwali F, Marshall JC, Parodo J, Farine D, Lye SJ, Ritchie JW, Rotstein OD (1999) Maternal neutrophil apoptosis in normal pregnancy, preeclampsia, and normotensive intrauterine growth restriction. Am J Obstet Gynecol 181(2):408-414. https://doi.org/10.1016/s00029378(99)70570-3

57. Sharp AN, Heazell AE, Crocker IP, Mor G (2010) Placental apoptosis in health and disease. Am J Reprod Immunol 64(3):159-169. https://doi.org/10.1111/j.1600-0897.2010. 00837.x

58. Allaire AD, Ballenger KA, Wells SR, McMahon MJ, Lessey BA (2000) Placental apoptosis in preeclampsia. Obstet Gynecol 96(2):271-276. https://doi.org/10.1016/s0029-7844(00)00895-4

59. Heazell AE, Buttle HR, Baker PN, Crocker IP (2008) Altered expression of regulators of caspase activity within trophoblast of normal pregnancies and pregnancies complicated by preeclampsia. Reprod Sci 15(10):1034-1043. https://doi.org/10.1177/ 1933719108322438

60. Levy R, Smith SD, Yusuf K, Huettner PC, Kraus FT, Sadovsky Y, Nelson DM (2002) Trophoblast apoptosis from pregnancies complicated by fetal growth restriction is associated with enhanced p53 expression. Am J Obstet Gynecol 186(5):10561061. https://doi.org/10.1067/mob.2002.122250

61. Smith SC, Baker PN, Symonds EM (1997) Increased placental apoptosis in intrauterine growth restriction. Am J Obstet Gynecol 177(6):1395-1401. https://doi.org/10.1016/s00029378(97)70081-4

62. Brown DA, Perry JB, Allen ME, Sabbah HN, Stauffer BL, Shaikh SR, Cleland JGF, Colucci WS, Butler J, Voors AA, Anker SD, Pitt B, Pieske B, Filippatos G, Greene SJ, Gheorghiade M (2017) Mitochondrial function as a therapeutic target in heart failure. Nat Rev Cardiol 14(4):238-250. https://doi.org/ 10.1038/nrcardio.2016.203

63. Hall ME, George EM, Granger JP (2011) The heart during pregnancy. Rev Esp Cardiol 64(11):1045-1050. https://doi.org/ 10.1016/j.recesp.2011.07.009

64. Costantine MM (2014) Physiologic and pharmacokinetic changes in pregnancy. Front Pharmacol 5:65. https://doi.org/ 10.3389/fphar.2014.00065

65. Liu LX, Arany Z (2014) Maternal cardiac metabolism in pregnancy. Cardiovasc Res 101(4):545-553. https://doi.org/10. 1093/cvr/cvu009

66. Cheung KL, Lafayette RA (2013) Renal physiology of pregnancy. Adv Chronic Kidney Dis 20(3):209-214. https://doi. org/10.1053/j.ackd.2013.01.012

67. Davison JM, Dunlop W (1980) Renal hemodynamics and tubular function normal human pregnancy. Kidney Int 18(2):152161. https://doi.org/10.1038/ki.1980.124

68. Sugden MC, Changani KK, Bentley J, Holness MJ (1992) Cardiac glucose metabolism during pregnancy. Biochem Soc Trans 20(2):195S. https://doi.org/10.1042/bst020195s

69. Brite J, Laughon SK, Troendle J, Mills J (2014) Maternal overweight and obesity and risk of congenital heart defects in offspring. Int J Obes (Lond) 38(6):878-882. https://doi.org/10. 1038/ijo.2013.244

70. Larsen TD, Sabey KH, Knutson AJ, Gandy TCT, Louwagie EJ, Lauterboeck L, Mdaki KS, Baack ML (2019) Diabetic pregnancy and maternal high-fat diet impair mitochondrial dynamism in the developing fetal rat heart by sex-specific mechanisms. Int J Mol Sci. https://doi.org/10.3390/ijms20123090

71. Mahesh E, Puri S, Varma V, Madhyastha PR, Bande S, Gurudev KC (2017) Pregnancy-related acute kidney injury: an analysis of 165 cases. Indian J Nephrol 27(2):113-117. https:// doi.org/10.4103/0971-4065.194394

72. Popkov VA, Andrianova NV, Manskikh VN, Silachev DN, Pevzner IB, Zorova LD, Sukhikh GT, Plotnikov EY, Zorov DB (2018) Pregnancy protects the kidney from acute ischemic injury. Sci Rep 8(1):14534. https://doi.org/10.1038/ s41598-018-32801-8 
73. Vaka VR, McMaster KM, Cunningham MW Jr, Ibrahim T, Hazlewood R, Usry N, Cornelius DC, Amaral LM, LaMarca B (2018) Role of mitochondrial dysfunction and reactive oxygen species in mediating hypertension in the reduced uterine perfusion pressure rat model of preeclampsia. Hypertension 72(3):703-711. https://doi.org/10.1161/HYPERTENSIONAHA. 118.11290

74. Williamson RD, McCarthy FP, Manna S, Groarke E, Kell DB, Kenny LC, McCarthy CM (2020) L-(+)-ergothioneine significantly improves the clinical characteristics of preeclampsia in the reduced uterine perfusion pressure rat model. Hypertension 75(2):561-568. https://doi.org/10.1161/HYPERTENSIONAHA. 119.13929

75. Cunningham MW Jr, Vaka VR, McMaster K, Ibrahim T, Cornelius DC, Amaral L, Campbell N, Wallukat G, McDuffy S, Usry N, Dechend R, LaMarca B (2019) Renal natural killer cell activation and mitochondrial oxidative stress; new mechanisms in AT1-AA mediated hypertensive pregnancy. Pregnancy Hypertens 15:72-77. https://doi.org/10.1016/j.preghy.2018.11.004

76. Wibom R, Hultman E, Johansson M, Matherei K, ConstantinTeodosiu D, Schantz PG (1992) Adaptation of mitochondrial ATP production in human skeletal muscle to endurance training and detraining. J Appl Physiol 73(5):2004-2010. https://doi.org/ 10.1152/jappl.1992.73.5.2004

77. Zou T, Yu B, Yu J, Mao X, Zheng P, He J, Huang Z, Liu Y, Chen D (2016) Moderately decreased maternal dietary energy intake during pregnancy reduces fetal skeletal muscle mitochondrial biogenesis in the pigs. Genes Nutr 11:19. https://doi.org/10.1186/ s12263-016-0535-1

78. Sanchez-Aranguren LC, Prada CE, Riano-Medina CE, Lopez M (2014) Endothelial dysfunction and preeclampsia: role of oxidative stress. Front Physiol 5:372. https://doi.org/10.3389/fphys. 2014.00372

79. Langley-Evans SC (2009) Nutritional programming of disease: unravelling the mechanism. J Anat 215(1):36-51. https://doi.org/ 10.1111/j.1469-7580.2008.00977.x

80. Roberts JM, August PA, Bakris G, Barton JR, Bernstein IM, Druzin M, Gaiser RR, Granger JP, Jeyabalan A, Johnson DD, Karumanchi SA, Lindheimer M, Owens MY, Saade GR, Sibai BM, Spong CY, Tsigas E, Joseph GE, O'Reilly N, Politzer A, Son S, Ngaiza K (2013) Hypertension in pregnancy. Report of the American College of Obstetricians and Gynecologists' task force on hypertension in pregnancy. Obstet Gynecol 122(5):1122-1131. https://doi.org/10.1097/01.Aog.0000437382. 03963.88

81. Levine RJ, Lam C, Qian C, Yu KF, Maynard SE, Sachs BP, Sibai BM, Epstein FH, Romero R, Thadhani R, Karumanchi SA, Group CS (2006) Soluble endoglin and other circulating antiangiogenic factors in preeclampsia. N Engl J Med 355(10):9921005. https://doi.org/10.1056/NEJMoa055352

82. Holland OJ, Cuffe JSM, Dekker Nitert M, Callaway L, Kwan Cheung KA, Radenkovic F, Perkins AV (2018) Placental mitochondrial adaptations in preeclampsia associated with progression to term delivery. Cell Death Dis 9(12):1150. https://doi.org/ 10.1038/s41419-018-1190-9

83. Yu J, Guo X, Chen R, Feng L (2016) Downregulation of mitofusin 2 in placenta Is related to preeclampsia. Biomed Res Int 2016:6323086. https://doi.org/10.1155/2016/6323086

84. Zhou X, Han TL, Chen H, Baker PN, Qi H, Zhang H (2017) Impaired mitochondrial fusion, autophagy, biogenesis and dysregulated lipid metabolism is associated with preeclampsia. Exp Cell Res 359(1):195-204. https://doi.org/10.1016/j.yexcr.2017. 07.029

85. Holland O, Dekker Nitert M, Gallo LA, Vejzovic M, Fisher JJ, Perkins AV (2017) Review: placental mitochondrial function and structure in gestational disorders. Placenta 54:2-9. https://doi. org/10.1016/j.placenta.2016.12.012

86. Yung HW, Colleoni F, Dommett E, Cindrova-Davies T, Kingdom J, Murray AJ, Burton GJ (2019) Noncanonical mitochondrial unfolded protein response impairs placental oxidative phosphorylation in early-onset preeclampsia. Proc Natl Acad Sci USA 116(36):18109-18118. https://doi.org/10.1073/pnas.1907548116

87. Muralimanoharan S, Maloyan A, Mele J, Guo C, Myatt LG, Myatt L (2012) MIR-210 modulates mitochondrial respiration in placenta with preeclampsia. Placenta 33(10):816-823. https:// doi.org/10.1016/j.placenta.2012.07.002

88. Myatt L, Muralimanoharan S, Maloyan A (2014) Effect of preeclampsia on placental function: influence of sexual dimorphism, microRNA's and mitochondria. Adv Exp Med Biol 814:133-146. https://doi.org/10.1007/978-1-4939-1031-1_12

89. Shi Z, Long W, Zhao C, Guo X, Shen R, Ding H (2013) Comparative proteomics analysis suggests that placental mitochondria are involved in the development of pre-eclampsia. PLoS ONE 8(5):e64351. https://doi.org/10.1371/journal.pone.0064351

90. Chandra I, Sun L (2018) Preterm and term preeclampsia: differences in biochemical parameter and pregnancy outcomes. Postgrad Med 130(8):703-707. https://doi.org/10.1080/00325 481.2018.1527169

91. Robinson CJ, Johnson DD, Chang EY, Armstrong DM, Wang W (2006) Evaluation of placenta growth factor and soluble Fms-like tyrosine kinase 1 receptor levels in mild and severe preeclampsia. Am J Obstet Gynecol 195(1):255-259. https://doi.org/10.1016/j. ajog.2005.12.049

92. Han YW, Yang Z, Ding XY, Yu H (2015) Differences in liver injury and trophoblastic mitochondrial damage in different preeclampsia-like mouse models. Chin Med J (Engl) 128(12):16271635. https://doi.org/10.4103/0366-6999.158322

93. Jiang Z, Zou Y, Ge Z, Zuo Q, Huang SY, Sun L (2015) A role of sFlt-1 in oxidative stress and apoptosis in human and mouse pre-eclamptic trophoblasts. Biol Reprod 93(3):73. https://doi.org/ 10.1095/biolreprod.114.126227

94. Erlandsson L, Ducat A, Castille J, Zia I, Kalapotharakos G, Hedstrom E, Vilotte JL, Vaiman D, Hansson SR (2019) Alpha-1 microglobulin as a potential therapeutic candidate for treatment of hypertension and oxidative stress in the STOX1 preeclampsia mouse model. Sci Rep 9(1):8561. https://doi.org/10.1038/ s41598-019-44639-9

95. McCarthy C, Kenny LC (2016) Therapeutically targeting mitochondrial redox signalling alleviates endothelial dysfunction in preeclampsia. Sci Rep 6:32683. https://doi.org/10.1038/srep3 2683

96. Illsinger S, Janzen N, Sander S, Schmidt KH, Bednarczyk J, Mallunat L, Bode J, Hagebolling F, Hoy L, Lucke T, Hass R, Das AM (2010) Preeclampsia and HELLP syndrome: impaired mitochondrial function in umbilical endothelial cells. Reprod Sci 17(3):219-226. https://doi.org/10.1177/1933719109351597

97. Vaka VR, Cunningham MW, Deer E, Franks M, Ibrahim T, Amaral LM, Usry N, Cornelius DC, Dechend R, Wallukat G, LaMarca BD (2020) Blockade of endogenous angiotensin II type I receptor agonistic autoantibody activity improves mitochondrial reactive oxygen species and hypertension in a rat model of preeclampsia. Am J Physiol Regul Integr Comp Physiol 318(2):R256R262. https://doi.org/10.1152/ajpregu.00179.2019

98. Gurugubelli Krishna R, Vishnu Bhat B (2018) Molecular mechanisms of intrauterine growth restriction. J Matern Fetal Neonatal Med 31(19):2634-2640. https://doi.org/10.1080/14767058.2017. 1347922

99. Mando C, De Palma C, Stampalija T, Anelli GM, Figus M, Novielli C, Parisi F, Clementi E, Ferrazzi E, Cetin I (2014) Placental mitochondrial content and function in intrauterine growth 
restriction and preeclampsia. Am J Physiol Endocrinol Metab 306(4):E404-413. https://doi.org/10.1152/ajpendo.00426.2013

100. Rashid CS, Bansal A, Simmons RA (2018) Oxidative stress, intrauterine growth restriction, and developmental programming of type 2 diabetes. Physiology (Bethesda) 33(5):348-359. https:// doi.org/10.1152/physiol.00023.2018

101. Lattuada D, Colleoni F, Martinelli A, Garretto A, Magni R, Radaelli T, Cetin I (2008) Higher mitochondrial DNA content in human IUGR placenta. Placenta 29(12):1029-1033. https:// doi.org/10.1016/j.placenta.2008.09.012

102. Guitart-Mampel M, Juarez-Flores DL, Youssef L, Moren C, Garcia-Otero L, Roca-Agujetas V, Catalan-Garcia M, Gonzalez-Casacuberta I, Tobias E, Milisenda JC, Grau JM, Crispi F, Gratacos E, Cardellach F, Garrabou G (2019) Mitochondrial implications in human pregnancies with intrauterine growth restriction and associated cardiac remodelling. J Cell Mol Med 23(6):3962-3973. https://doi.org/10.1111/jcmm.14282

103. Sood R, Zehnder JL, Druzin ML, Brown PO (2006) Gene expression patterns in human placenta. Proc Natl Acad Sci USA 103(14):5478-5483. https://doi.org/10.1073/pnas.0508035103

104. Jones R, Pena J, Mystal E, Marsit C, Lee MJ, Stone J, Lambertini L (2020) Mitochondrial and glycolysis-regulatory gene expression profiles are associated with intrauterine growth restriction. J Matern Fetal Neonatal Med 33(8):1336-1345. https://doi.org/ $10.1080 / 14767058.2018 .1518419$

105. Formanowicz D, Malinska A, Nowicki M, Kowalska K, GrucaStryjak K, Breborowicz G, Korybalska K (2019) Preeclampsia with intrauterine growth restriction generates morphological changes in endothelial cells associated with mitochondrial swelling-an in vitro study. J Clin Med. https://doi.org/10.3390/ jcm8111994

106. Peterside IE, Selak MA, Simmons RA (2003) Impaired oxidative phosphorylation in hepatic mitochondria in growth-retarded rats. Am J Physiol Endocrinol Metab 285(6):E1258-1266. https://doi. org/10.1152/ajpendo.00437.2002

107. Liu J, Chen D, Yao Y, Yu B, Mao X, He J, Huang Z, Zheng P (2012) Intrauterine growth retardation increases the susceptibility of pigs to high-fat diet-induced mitochondrial dysfunction in skeletal muscle. PLoS ONE 7(4):e34835. https://doi.org/10. 1371/journal.pone.0034835

108. Beauchamp B, Thrush AB, Quizi J, Antoun G, McIntosh N, AlDirbashi OY, Patti ME, Harper ME (2015) Undernutrition during pregnancy in mice leads to dysfunctional cardiac muscle respiration in adult offspring. Biosci Rep. https://doi.org/10.1042/ BSR20150007

109. Diagnostic criteria and classification of hyperglycaemia first detected in pregnancy: a World Health Organization Guideline. Diabetes Res Clin Pract 103(3):341-363. https://doi.org/10. 1016/j.diabres.2013.10.012

110. Metzger BE, Phelps RL, Freinkel N, Navickas IA (1980) Effects of gestational diabetes on diurnal profiles of plasma glucose, lipids, and individual amino acids. Diabetes Care 3(3):402-409. https://doi.org/10.2337/diacare.3.3.402

111. Butte NF (2000) Carbohydrate and lipid metabolism in pregnancy: normal compared with gestational diabetes mellitus. Am J Clin Nutr 71(5 Suppl):1256S-1261S. https://doi.org/10.1093/ ajen/71.5.1256s

112. Muralimanoharan S, Maloyan A, Myatt L (2016) Mitochondrial function and glucose metabolism in the placenta with gestational diabetes mellitus: role of miR-143. Clin Sci (Lond) 130(11):931941. https://doi.org/10.1042/CS20160076

113. Abbade J, Klemetti MM, Farrell A, Ermini L, Gillmore T, Sallais J, Tagliaferro A, Post M, Caniggia I (2020) Increased placental mitochondrial fusion in gestational diabetes mellitus: an adaptive mechanism to optimize feto-placental metabolic homeostasis? BMJ Open Diabetes Res Care. https://doi.org/10. 1136/bmjdrc-2019-000923

114. Ramirez-Emiliano J, Fajardo-Araujo ME, Zuniga-Trujillo I, Perez-Vazquez V, Sandoval-Salazar C, Ornelas-Vazquez JK (2017) Mitochondrial content, oxidative, and nitrosative stress in human full-term placentas with gestational diabetes mellitus. Reprod Biol Endocrinol 15(1):26. https://doi.org/10.1186/ s12958-017-0244-7

115. Boyle KE, Hwang H, Janssen RC, DeVente JM, Barbour LA, Hernandez TL, Mandarino LJ, Lappas M, Friedman JE (2014) Gestational diabetes is characterized by reduced mitochondrial protein expression and altered calcium signaling proteins in skeletal muscle. PLoS ONE 9(9):e106872. https://doi.org/10.1371/ journal.pone. 0106872

116. Kelley KW, Carroll DG, Meyer A (2015) A review of current treatment strategies for gestational diabetes mellitus. Drugs Context 4:212282. https://doi.org/10.7573/dic.212282

117. El-Mir MY, Nogueira V, Fontaine E, Averet N, Rigoulet M, Leverve $X$ (2000) Dimethylbiguanide inhibits cell respiration via an indirect effect targeted on the respiratory chain complex I. J Biol Chem 275(1):223-228. https://doi.org/10.1074/jbc.275.1.223

118. Committee on Practice Bulletins-Obstetrics (2013) Practice bulletin no. 137: gestational diabetes mellitus. Obstet Gynecol 122(2 PART 1):406-416. https://doi.org/10.1097/01.AOG.00004 33006.09219.f1

119. In: 2018 surveillance of diabetes in pregnancy: management from preconception to the postnatal period (NICE guideline NG3). London

120. Zielonka J, Joseph J, Sikora A, Hardy M, Ouari O, Vasquez-Vivar J, Cheng G, Lopez M, Kalyanaraman B (2017) Mitochondriatargeted triphenylphosphonium-based compounds: syntheses, mechanisms of action, and therapeutic and diagnostic applications. Chem Rev 117(15):10043-10120. https://doi.org/10.1021/ acs.chemrev.7b00042

121. Zinovkin RA, Zamyatnin AA (2019) Mitochondria-targeted drugs. Curr Mol Pharmacol 12(3):202-214. https://doi.org/10. 2174/1874467212666181127151059

122. Brownfoot FC, Hastie R, Hannan NJ, Cannon P, Nguyen TV, Tuohey L, Cluver C, Tong S, Kaitu'u-Lino TJ (2020) Combining metformin and sulfasalazine additively reduces the secretion of antiangiogenic factors from the placenta: Implications for the treatment of preeclampsia. Placenta 95:78-83. https://doi.org/ 10.1016/j.placenta.2020.04.010

123. Brownfoot FC, Hastie R, Hannan NJ, Cannon P, Tuohey L, Parry LJ, Senadheera S, Illanes SE, Kaitu'u-Lino TJ, Tong S (2016) Metformin as a prevention and treatment for preeclampsia: effects on soluble fms-like tyrosine kinase 1 and soluble endoglin secretion and endothelial dysfunction. Am J Obstet Gynecol 214(3):356.e351-356.e315. https://doi.org/10.1016/j.ajog.2015. 12.019

124. Kaitu'u-Lino TJ, Brownfoot FC, Beard S, Cannon P, Hastie R, Nguyen TV, Binder NK, Tong S, Hannan NJ (2018) Combining metformin and esomeprazole is additive in reducing sFlt-1 secretion and decreasing endothelial dysfunction-implications for treating preeclampsia. PLoS ONE 13(2):e0188845. https:// doi.org/10.1371/journal.pone.0188845

125. Wang F, Cao G, Yi W, Li L, Cao X (2019) Effect of metformin on a preeclampsia-like mouse model induced by high-fat diet. BioMed Res Int. https://doi.org/10.1155/2019/6547019

126. Cluver C, Walker SP, Mol BW, Hall D, Hiscock R, Brownfoot FC, Kaitu'u-Lino TJ, Tong S (2019) A double blind, randomised, placebo-controlled trial to evaluate the efficacy of metformin to treat preterm pre-eclampsia (PI2 Trial): study protocol. BMJ Open 9(4):e025809. https://doi.org/10.1136/bmjop en-2018-025809 
127. Chiswick C, Reynolds RM, Denison F, Drake AJ, Forbes S, Newby DE, Walker BR, Quenby S, Wray S, Weeks A, Lashen H, Rodriguez A, Murray G, Whyte S, Norman JE (2015) Effect of metformin on maternal and fetal outcomes in obese pregnant women (EMPOWaR): a randomised, double-blind, placebo-controlled trial. Lancet Diabetes Endocrinol 3(10):778-786. https:// doi.org/10.1016/S2213-8587(15)00219-3

128. Szczesny B, Modis K, Yanagi K, Coletta C, Le Trionnaire S, Perry A, Wood ME, Whiteman M, Szabo C (2014) AP39, a novel mitochondria-targeted hydrogen sulfide donor, stimulates cellular bioenergetics, exerts cytoprotective effects and protects against the loss of mitochondrial DNA integrity in oxidatively stressed endothelial cells in vitro. Nitric Oxide 41:120-130. https://doi. org/10.1016/j.niox.2014.04.008

129. Covarrubias AE, Lecarpentier E, Lo A, Salahuddin S, Gray KJ, Karumanchi SA, Zsengeller ZK (2019) AP39, a modulator of mitochondrial bioenergetics, reduces antiangiogenic response and oxidative stress in hypoxia-exposed trophoblasts: relevance for preeclampsia pathogenesis. Am J Pathol 189(1):104-114. https://doi.org/10.1016/j.ajpath.2018.09.007

130. Trnka J, Blaikie FH, Smith RA, Murphy MP (2008) A mitochondria-targeted nitroxide is reduced to its hydroxylamine by ubiquinol in mitochondria. Free Radic Biol Med 44(7):14061419. https://doi.org/10.1016/j.freeradbiomed.2007.12.036

131. Smith RA, Murphy MP (2010) Animal and human studies with the mitochondria-targeted antioxidant MitoQ. Ann N Y Acad Sci 1201:96-103. https://doi.org/10.1111/j.1749-6632.2010.05627.x

132. Murphy MP, Smith RA (2007) Targeting antioxidants to mitochondria by conjugation to lipophilic cations. Annu Rev Pharmacol Toxicol 47:629-656. https://doi.org/10.1146/annurev.pharm tox.47.120505.105110
133. Yang Y, Xu P, Zhu F, Liao J, Wu Y, Hu M, Fu H, Qiao J, Lin L, Huang B, Jin H, Liu X, Zheng Y, Wen L, Saffery R, Kilby MD, Yan J, Kenny LC, Qi H, Tong C, Baker PN (2020) The potent antioxidant MitoQ protects against preeclampsia during late gestation but increases the risk of preeclampsia when administered in early pregnancy. Antioxid Redox Signal. https://doi.org/10. 1089/ars.2019.7891

134. Zussman R, Xu LY, Damani T, Groom KM, Chen Q, Seers B, Viall CA, Chamley LW, Hickey A (2020) Antiphospholipid antibodies can specifically target placental mitochondria and induce ROS production. J Autoimmun. https://doi.org/10.1016/j.jaut. 2020.102437

135. Chow CK (2004) Dietary coenzyme Q10 and mitochondrial status. Methods Enzymol 382:105-112. https://doi.org/10.1016/ S0076-6879(04)82007-X

136. Teran E, Hernandez I, Nieto B, Tavara R, Ocampo JE, Calle A (2009) Coenzyme Q10 supplementation during pregnancy reduces the risk of pre-eclampsia. Int J Gynaecol Obstet 105(1):43-45. https://doi.org/10.1016/j.ijgo.2008.11.033

137. Xu X, Pan JR, Zhang YZ (2019) CoQ10 alleviate preeclampsia symptoms by enhancing the function of mitochondria in the placenta of pregnant rats with preeclampsia. Hypertens Pregnancy 38(4):217-222. https://doi.org/10.1080/10641955.2019.1649420

Publisher's Note Springer Nature remains neutral with regard to jurisdictional claims in published maps and institutional affiliations. 